\title{
Vagotomy inhibits the jejunal fluid secretion activated by luminal ileal Escherichia coli STa in the rat in vivo
}

\author{
V E Rolfe, R J Levin
}

\begin{abstract}
Background-Escherichia coli heat stable enterotoxin (STa) is a major cause of secretory diarrhoea in humans.

Aims-To assess the effects of instilling STa into the ileum on remote fluid secretion in the jejunum and colon in rats in vivo by a gravimetric technique.

Methods and results-Ileal STa (55 ng/ml) stimulated fluid secretion in both ileal and jejunal loops but not in the colon. The fluid secretion induced by ileal STa was inhibited by L-NAME ( $\boldsymbol{N}^{\omega}$-nitro-Larginine methyl ester, $40 \mathrm{mg} / \mathrm{kg}$ intraperitoneally) but not by D-NAME ( $N^{w}$-nitro-Darginine methyl ester). Ileal carbachol $(183 \mathrm{mg} / \mathrm{ml})$ instilled into the lumen stimulated ileal secretion but not jejunal secretion, and was unaffected by L-NAME. Capsaicin $(10 \mu M)$, instilled luminally with STa in the ileum, blocked both the ileal and jejunal fluid secretion. Acute bilateral vagotomy prevented luminal ileal STa from inducing jejunal fluid secretion but not from activating ileal fluid secretion.

Conclusion-Ileal $E$ coli STa stimulates remote secretion in the rat jejunum but not in the colon, probably by a nitrinergic, vagal reflex mediated by $C$ fibres. This neural pathway will amplify the action of the toxin in its generation of secretory diarrhoea.

(Gut 1999;44:615-619)
\end{abstract}

Keywords: intestinal fluid secretion; Escherichia coli STa; vagus; nitric oxide; $\mathrm{C}$ fibres

Escherichia coli heat stable enterotoxin (STa) is a major cause of human secretory diarrhoea. It induces electrogenic $\mathrm{Cl}^{-}$secretion and inhibits $\mathrm{NaCl}$ absorption in the small intestine, ${ }^{1}$ acting by binding to, and activating guanylate cyclase at the luminal membrane which elevates enterocyte cyclic GMP. ${ }^{2}$ The enteric nervous system also participates in its action by creating a fluid secretion when both STa and STb are instilled into the jejunum of rats and cats. ${ }^{3}$ Studies in vitro confirmed that STa could act indirectly to cause electrogenic secretion through a neural mechanism which was shown to involve a nitrinergic, myenteric, secretory reflex mediated by $\mathrm{C}$ afferent fibres, and that the activation of fluid secretion by STa in vivo could be blocked by pretreatment with L-NAME ( $N^{\omega}$-nitro-L-arginine methyl ester). ${ }^{4}$ The mechanism of activation of the $\mathrm{C}$ fibres by
STa is unknown, but it may involve the release of trigger substance(s) from the enterocytes or other cells of the intestinal epithelium. Nzegwu and Levin have recently reported that the NK2 tachykinin receptor antagonist MEN 10627 specifically inhibited fluid secretion activated by $E$ coli $S T$ in rat jejunum in vivo. ${ }^{5}$

Numerous C fibres originate from the intestine with their cell bodies in the dorsal root ganglion and the fibres enter the spinal cord between segments $\mathrm{T} 1$ and L2. ${ }^{6}$ In addition, ileal sensory afferent fibres enter the nucleus of the tractus solitarius in the brainstem via the vagus in the rat. ${ }^{7}$ The pattern of innervation suggests that $E$ coli STa placed in the lumen of the ileum may induce secretion reflexively not only in the ileum but also in a remote part of the intestine by mediation of $\mathrm{C}$ fibres.

We thus investigated whether the stimulation of afferents by luminal STa in the rat ileum in vivo influenced secretion in a jejunal segment with no luminal STa. Preliminary data have been reported to the Physiological Society.

\section{Materials and methods}

MEASUREMENT OF FLUID TRANSPORT IN VIVO

Fed, male albino rats (body weight 230-250 g, Sheffield University Strain) were anaesthetised with $\mathrm{Na}^{+}$pentobarbitone $(60 \mathrm{mg} / \mathrm{kg}$ body weight intraperitoneally). Fluid transport $(\mathrm{g} / \mathrm{g}$ gut dry weight $/ \mathrm{h}$ ) was measured gravimetrically for 30 minutes as described previously ${ }^{4}$ in 10 $\mathrm{cm}$ tied off loops of mid-ileum, mid-jejunum, and a $5 \mathrm{~cm}$ loop of mid-colon. The "stimulating" loop was at least $10 \mathrm{~cm}$ arboral to the jejunal loop and contained $0.8 \mathrm{ml}$ of $0.9 \% \mathrm{NaCl}$ with either STa (55 ng/ml), carbachol (183 $\mathrm{mg} / \mathrm{ml})$, D- or L-arginine $(20 \mathrm{mg} / \mathrm{ml})$, or together with capsaicin $(10 \mu \mathrm{M})$. The "indicator" jejunal or mid-colonic loops contained either $0.8 \mathrm{ml}$ or $0.4 \mathrm{ml}$ of $0.9 \% \mathrm{NaCl}$ respectively. Some rats were pretreated with either L- or D-NAME $(40 \mathrm{mg} / \mathrm{kg}$ body weight intraperitoneally) 15 minutes before luminal instillation of the fluids. A number of rats were acutely, surgically vagotomised in the neck under the pentobarbitone anaesthesia and a cannula placed in the trachea; they were then used immediately for the secretion experiments. Sham operated controls had identical surgery except that the carotid/vagal complex was manipulated with blunt scissors. The rats

Abbreviations used in this paper: D-NAME, $N^{\omega}$-nitro-D-arginine methyl ester; L-NAME, $N^{\omega}$-nitro-L-arginine methyl ester; STa, Escherichia coli heat stable enterotoxin. 
Table 1 Effects of ileal STa $(55 \mathrm{ng} / \mathrm{ml})$ and carbachol $(183 \mathrm{mg} / \mathrm{ml})$, and pretreatment of rats with $L_{-}$or $D-N A M E(40 \mathrm{mg} / \mathrm{kg})$ on fluid transport in the ileum and a saline filled jejunal loop

\begin{tabular}{llll}
\hline & \multicolumn{3}{l}{$g$ fluid/g gut dry wt/h } \\
\cline { 2 - 4 } Treatment & Ileal content & Stimulating loop Ileum & Indicator loop fejumum \\
\hline D-NAME & STa & $+0.8(0.5)(\mathrm{n}=8)^{\star \star \star}$ & $+0.5(0.2)(\mathrm{n}=8)^{\star \star \star}$ \\
L-NAME & STa & $-1.6(0.2)(\mathrm{n}=8)^{\star \star \star}$ & $-1.1(0.3)(\mathrm{n}=8)^{\star \star \star}$ \\
D-NAME & Carbachol & $+2.0(0.3)(\mathrm{n}=6)$ & $-1.5(0.5)(\mathrm{n}=6)$ \\
L-NAME & Carbachol & $+2.6(1.0)(\mathrm{n}=6)$ & $-1.6(0.6)(\mathrm{n}=6)$ \\
\hline
\end{tabular}

Results expressed as mean (SEM); number of rats in brackets.

Net absorption is shown as a negative fluid movement and secretion as a positive fluid movement. ${ }^{\star \star \star} \mathrm{p}<0.001, \mathrm{D}-\mathrm{NAME}$ versus L-NAME.

were killed after use by anaesthetic overdose, thoracotomy, and heart incision.

STATISTICS

Results are given as the mean (SEM) fluid transport with the numbers of rats used in brackets. Absorption was regarded as a negative fluid transport and secretion as a positive fluid transfer. Statistical significance of the results was tested using Student's unpaired $t$ test and multiple comparisons were made by ANOVA with significance accepted at $\mathrm{p}<0.05$.

CHEMICALS

All chemicals were obtained from Sigma (Poole, Dorset, UK).

\section{Results}

ILEAL AND JEJUNAL FLUID TRANSPORT IN VIVO When saline was placed in both ileal and jejunal loops in control, untreated rats the fluid transport observed was that of net absorption which was not significantly different (ileum $-8.4(1.5)(\mathrm{n}=4)$ versus jejunum $-5.5(1.5)$ $(\mathrm{n}=4) \mathrm{g}$ fluid/g gut dry weight/h, $\mathrm{p}>0.05)$. Instillation of L-arginine $(20 \mathrm{mg} / \mathrm{ml})$, a substrate for nitric oxide synthesis, into the ileum, induced fluid secretion not only in the ileum but also in the jejunum which had only $0.9 \%$ $\mathrm{NaCl}$ instilled (ileum $3.4(2.5)(\mathrm{n}=4)$ versus jejunum $2.2(2.4) \quad(\mathrm{n}=4) \mathrm{g}$ fluid/g gut dry weight $/ \mathrm{h})$. Ileal instillation of $\mathrm{D}$-arginine $(20$ $\mathrm{mg} / \mathrm{ml}$ ), however, had no effect on the usual absorption for fluid in the ileum and jejunum (ileum -6.1 (1.8) $(n=6)$ versus jejunum -3.4 (0.9) $(\mathrm{n}=6) \mathrm{g}$ fluid/g gut dry weight/h).

Table 2 Effects of bilateral vagotomy on ileal and jejunal fluid movement

\begin{tabular}{lll}
\hline & \multicolumn{2}{l}{ g fluid/g gut dry wt/h } \\
\cline { 2 - 3 } & Ileum (STa) & fejunum $(\mathrm{NaCl})$ \\
\hline Sham operated control & $+3.3(1.3)(\mathrm{n}=5)$ & $+1.1(0.1)(\mathrm{n}=5)^{\star}$ \\
Vagotomised & $+2.8(0.8)(\mathrm{n}=6)$ & $-0.9(0.5)(\mathrm{n}=6)^{\star}$ \\
\hline
\end{tabular}

Ileum contained STa $(55 \mathrm{ng} / \mathrm{ml})$ and jejunum contained $0.9 \%$ saline.

Results are given as mean (SEM); number of rats in brackets.

Net secretion is shown as a positive fluid movement while net absorption is shown as a negative fluid movement. ${ }^{\star} \mathrm{p}<0.02$, control versus vagotomised.

Table 3 Effects of luminal STa and STa plus capsaicin $(10 \mu M)$ in the stimulatory ileal loop on fluid movements in the ileum, jejunum, and colon

\begin{tabular}{llll}
\hline \multirow{4}{*}{ Treatment } & \multicolumn{2}{l}{ g fluid/g gut dry wt/h } & \\
\cline { 2 - 4 } & Ileum $(\mathrm{STa})$ & fejunum $(\mathrm{NaCl})$ & Colon $(\mathrm{NaCl})$ \\
\hline Control & $+2.3(1.5)(\mathrm{n}=6)^{\star}$ & $+0.5(1.0)(\mathrm{n}=6)^{\star \star}$ & $-4.1(4.2)(\mathrm{n}=6)$ \\
Capsaicin & $-2.1(1.7)(\mathrm{n}=6)^{\star}$ & $-4.3(0.9)(\mathrm{n}=6)^{\star \star}$ & $-5.3(0.7)(\mathrm{n}=5)$ \\
\hline
\end{tabular}

Results expressed as mean (SEM); number of rats in brackets.

Net secretion is shown as positive fluid movement and absorption as negative fluid movement. ${ }^{\star} \mathrm{p}<0.05$, control versus capsaicin; ${ }^{\star \star} \mathrm{p}<0.01$, control versus capsaicin.
EFFECTS OF D- AND L-NAME ON FLUID SECRETION INDUCED BY STA AND CARBACHOL

Table 1 shows the effects of D- and L-NAME treatment on the fluid secretion induced by ileal STa and carbachol. Instillation of STa into the ileum of D-NAME pretreated rats induced secretion in both the ileal and jejunal loops. L-NAME, however, inhibited the secretory action of STa in the ileum and jejunum and net absorption resulted which was significantly different from D-NAME controls $(\mathrm{p}<0.001)$. Ileal luminal carbachol induced secretion only in the ileum, having no significant effect on the absorption of the jejunum. This secretory action of luminal carbachol in the ileum was unaffected by L-NAME treatment compared with D-NAME.

\section{EFFECTS OF BILATERAL VAGOTOMY ON FLUID}

SECRETION INDUCED BY STa

Table 2 shows the effect of vagotomy on the ability of ileal STa to induce secretion in the jejunum. In the control sham operated group, ileal STa not only induced a significant fluid secretion in the ileal loop but also induced secretion in the jejunum. However, in the vagotomised group, although ileal STa induced a fluid secretion in the ileum it had no effect on the jejunal loop which displayed absorption, significantly different from sham operated controls $(p<0.02)$.

EFFECTS OF LUMINAL CAPSAICIN ON STA INDUCED FLUID SECRETION

Table 3 shows the effect of luminal capsaicin on the ability of ileal STa to induce jejunal and colonic fluid secretion. Control luminal STa in the ileum induced significant secretion in both the ileal loop and the jejunal loop but not in the colon which displayed absorption. When capsaicin $(10 \mu \mathrm{M})$ was added to the STa, a significant reduction in fluid secretion was observed in the stimulating ileal loop $(\mathrm{p}<0.05)$ and in the indicator jejunal loop $(\mathrm{p}<0.01)$ where net absorption occurred. Colonic absorption was unchanged by the ileal capsaicin.

EFFECT OF BILATERAL VAGOTOMY AND CAPSAICIN ON BASAL FLUID TRANSPORT

Neither bilateral vagotomy nor capsaicin altered basal fluid transport compared with control ileum and jejunum (control ileum -4.3 (1.4) $(n=4)$ versus vagotomised $-2.6(0.6)$ $(n=4)$ versus capsaicin $-2.5(0.7) \quad(n=4) \mathrm{g}$ fluid/g gut dry weight/h, p>0.05, ANOVA; and control jejunum $-1.8 \quad(1.1) \quad(n=4)$ versus vagotomised $-1.8(1.5)(n=4)$ versus capsaicin -4.0 (1.2) g fluid/g gut dry weight/h, p>0.05, ANOVA).

\section{Discussion}

$E$ coli STa stimulates a myenteric secretory reflex in the rat ileum mediated by capsaicin sensitive $\mathrm{C}$ fibres. ${ }^{4}$ The gastrointestinal tract is extensively innervated by vagal and spinal afferent fibres, ${ }^{6}$ a pattern of afferent innervation that suggests that $E$ coli STa placed in the lumen may activate secretion in remote intestinal regions not in contact with the toxin. Our results confirmed this, clearly showing that 
instillation of the enterotoxin STa into the rat ileum activated both ileal and jejunal fluid secretion and both could be inhibited by the nitric oxide synthase inhibitor L-NAME but not the inactive isomer D-NAME. Instillation of the cholinergic agonist carbachol into the ileum lumen activated ileal secretion but had no significant effect on jejunal fluid transport, and furthermore, was unaffected by L-NAME. Thus, non-specific systemic effects of L-NAME could not be the cause of the inhibition of the STa induced jejunal fluid secretion. Instillation of the nitric oxide synthase substrate L-arginine into the ileum also induced both ileal and jejunal secretion, but equivalent D-arginine did not alter fluid transport, indicating that the fluid secretion induced was not an osmotic effect. Recently, the nitric oxide (NO) synthase cofactor tetrahydrobiopterin was implicated in the regulation of electrogenic secretion stimulated by STa and L-arginine in the mouse ileum in vitro. ${ }^{9}$ This strongly suggests that $\mathrm{NO}$ is involved in intestinal secretion, and our present results show that NO is implicated in the activation of remote jejunal secretion.

It should be mentioned that the experimental evidence for the regulating role of nitric oxide in small intestinal fluid secretion (prosecretory) or absorption (proabsorptive) in vivo is conflicting. Practically all the evidence relies on the use of either L-NAME as an inhibitor of $\mathrm{NO}$ generation and on $\mathrm{NO}$ donors and interpretation of their actions on basal and secretagogue induced fluid transport. Rolfe and Levin ${ }^{4}$ were the first to report that in the rat in vivo STa induced fluid secretion was inhibited by the intraperitoneal injection of L-NAME. Gaginella and colleagues ${ }^{10}$ and Izzo and colleagues ${ }^{11}$ also found that in the rat intraperitoneal or subcutaneous injected L-NAME inhibited the fluid secretion induced by bisacodyl and phenolphthalein in the former, and by senna and cascara in the latter. All these studies thus indicated a prosecretory role for NO. In later in vivo rat experiments, ${ }^{12}$ however, L-NAME enhanced the fluid secretory effect of luminal STa interpreted as a proabsorptive action of NO. In a study by Qui and colleagues $^{13}$ NOS inhibitors augmented the ileal secretion induced by Clostridium difficile toxin A in the rat. We cannot explain the clearly contradictory findings of these authors but it may be simply due to differences in the method of administering the inhibitor L-NAME. In these studies the antagonist was given by continuous venous infusion. This type of administration may cause L-NAME to have different actions than when it is injected subcutaneously or intraperitoneally in slug doses. However, despite the contradictory findings about the possible role of NO in fluid transport, they do not influence the basic finding of the present experiments that luminal STa in the ileum activates remote secretion in the jejunum through a neural mechanism.

Previous in vitro studies ${ }^{414}$ showed that mucosal STa induced ileal electrogenic secretion that was blocked in the presence of capsaicin only in ileal preparations where the myenteric plexus was intact and in communi- cation with the submucosal plexus. This indicated that the action of STa was mediated by afferent fibres which connected with the myenteric plexus. Furthermore, the action of the toxin was also blocked by L-NAME only when the myenteric plexus was present, suggesting that the secretory efferent pathway may have had a nitrinergic component, although we cannot exclude a nitrinergic afferent component. Fluid secretion activated by STa in vivo was also inhibited by L-NAME in the rat ileum $^{4}$ and by luminal capsaicin in the jejunum, ileum, and colon. ${ }^{15}$ It is interesting in this context to find that the myenteric plexus is also implicated in the secretion of fluid induced by cholera toxin in the rat jejunum. ${ }^{16}$

In the present experiments in vivo, placing capsaicin with the STa in the ileal loop prevented the fluid secretion both in the ileal and jejunal loop, while capsaicin alone did not influence basal absorption. Capsaicin selectively targets sensory afferent fibres ${ }^{17}$; thus it appears that mediation of $\mathrm{C}$ fibres is essential for STa ileal activated jejunal secretion to be induced. The Clostridium difficile toxin A also causes fluid secretion inhibited by capsaicin treatment whereas cholera toxin appears unaffected. ${ }^{18}$ As mentioned previously, Nzegwu and Levin ${ }^{5}$ have recently shown the involvement of the tachykinin receptor NK2 in the action of STa; it is therefore possible that the activation is via a released tachykinin(s). Thus, a toxin specific trigger mechanism activates mucosal afferent fibres but the exact mechanical or chemical nature of these substances has still to be established.

Our results show that bilateral vagotomy prevented ileal STa from inducing jejunal secretion, but had no effect on the activation of ileal secretion by STa. Furthermore, bilateral vagotomy did not affect the basal absorption in either the ileum or jejunum. The STa toxin in the ileal loop must activate jejunal secretion either by neural mediation via the cord and vagal efferents, or by vagal afferents and efferents. Further investigations are necessary to characterise fully the afferent neural pathways involved and to determine whether there is bipolarity of activationthat is, whether the STa ileal activation of jejunal secretion can be mirrored by a similar STa jejunal activation of ileal secretion. Anterograde labelling techniques have allowed the organisation of intestinal reflexes to be viewed, and ileal afferent fibres have been shown to converge on the dorsal motor nucleus of the vagus in the rat. ${ }^{7}$ Here, efferent vagal neurones project to the intrinsic intestinal ganglia and structures in the brain, thus coordinating intestinal functions. The routes may provide a central pathway for the activation of remote jejunal secretion by ileal STa.

Although the ileal STa clearly induces secretion in both the ileum and jejunum, we did not observe any activation of fluid secretion in the mid-colon which contrasts with a study using cholera toxin. ${ }^{19}$ The group reported that instillation of cholera toxin into the rat jejunum evoked not only jejunal fluid secretion but colonic secretion as well. In this study transection of the intestine to isolate the colon 
actually caused an inhibition of cholera toxin stimulated colonic secretion, suggesting that the normal stimulatory mechanism was via the enteric nervous system. However studies in the guinea pig have suggested that individual neurones only have a short (approximately $12 \mathrm{~mm}$ ) projection. ${ }^{20}$ The jejunum in the rat could be some 30-40 cm away, a remarkably long projection. At present it is not possible to characterise the method of neural transmission that STa uses to activate remote secretion. Another study did not show a remote effect to mucosal $\mathrm{STa}$ in rabbit ileum in vitro. Hubel and colleagues ${ }^{21}$ were unable to show any activation of electrogenic secretion in a segment of small intestine located about $0.4 \mathrm{~cm}$ distal to a stimulating segment in contact with STa, but their in vitro experiments were conducted with the intestine stripped of its outer muscle which removes the myenteric plexus, thus removing neural connections which in the rat are known to mediate the secretory reflex. In our experiments, while severing the vagus reduced the remote fluid secretion jejunally, we cannot completely rule out the enteric nervous system. However this has to be mediated by $\mathrm{C}$ fibre activity.

One intriguing feature of the activation of fluid secretion in vivo by $E$ coli STa is that it can be either totally or very severely reduced by treatment with either luminal capsaicin ${ }^{14}$ or by pretreatment of the rat with $\mathrm{L}-\mathrm{NAME}^{8}$ (confirmed by present results). This suggests strongly that in vivo the mediation of electrogenic $\mathrm{Cl}^{-}$secretion by STa activating guanylate cyclase and generating cyclic GMP in the enterocytes is not an important ionic driving force for fluid secretion. Early studies ${ }^{3}$ first drew attention to the fact that part of the fluid secretion activated by STa in vivo was through the nervous system. Jodal ${ }^{22}$ suggested that $60-70 \%$ of the fluid secretion was so mediated, although in some cases nearly total inhibition was observed using nerve blocking agents. In our present rat studies and in those previously mentioned, capsaicin and L-NAME often show such total inhibition of STa activated fluid secretion. It thus seems likely that the usual mechanism of activation of net fluid secretion by luminal STa in vivo is by the neural path and not by the direct action of STa on the enterocyte. A recent review ${ }^{23}$ may explain this paradox. While STa causes electrogenic $\mathrm{Cl}^{-}$ secretion by a direct action on villus enterocytes, according to Jodal and Lundgren the upper third of the villus interstitium exhibits such a high osmotic pressure, both in the absorptive and secretory state, that this hyperosmolarity prevents net fluid secretion across the villus. However, the luminal STa, by activating the $\mathrm{C}$ fibre reflex mediated through the myenteric plexus and submucosal ganglion, induces the crypts to secrete $\mathrm{Cl}^{-}$and fluid in the latter moving into the lumen because the interstitial osmolarity around the crypts is far less than in the upper villus. Using the intestine in vitro, especially with muscle stripped preparations devoid of the myenteric plexus (thus $\mathrm{C}$ fibre mediated secretion) and only measuring the short circuit current as an index of secretion creates conditions that emphasise the direct action of STa on the enterocytes to create the electrogenic secretion. It is only when the myenteric plexus is present (intact intestine in vitro and in vivo) that STa can activate electrogenic ion and fluid secretion from the crypts. Interestingly, in the guinea pig small intestine, the excitatory postsynaptic potential input (the classical nicotinic receptor response) to the submucosal neurones is largely derived from the myenteric plexus ${ }^{24}$ and vagal efferent fibres only reach this plexus. ${ }^{25}$

The effect of this STa activated neural path may also be of importance in relation to the action(s) of the recently discovered endogenous intestinal secretagogue guanylin. While guanylin is a weaker endogenous ligand for the $E$ coli STa receptors one of the highest concentrations of intestinal guanylin is found in the ileum. ${ }^{26}$ Although there has been some contention as to the exact localisation of guanylin in the small intestine, the initial localisation in Paneth cells ${ }^{27}$ appears to have been an artefact; more recent studies have now localised it by immunocytochemistry in Goblet cells. ${ }^{28-30}$ The presence of guanylin in the lumen of the intestine has been reported. ${ }^{31}$ Presumably it is released when the Goblet cells discharge. It has been suggested that by activating fluid secretion it could make the discharged mucus more fluid and lubricative. Because guanylin is a weaker agonist than STa in inducing fluid secretion its putative physiological role in the ileal lumen activating remote secretion in the jejunum clearly needs investigation.

In conclusion, luminal STa in the ileum in vivo can activate fluid secretion in the jejunum but not in the colon, by a neural mechanism(s) that is inhibited by vagotomy, L-NAME, and capsaicin. This neural pathway(s) will clearly amplify the action of the toxin in its generation of secretory diarrhoea.

Part of this study was undertaken during the tenure of an MRC scholarship by V Rolfe in cooperation with Reckitt and Coleman, Kingston-upon-Hull, UK.

1 Guandolini A, Rao MC, Smith PL, et al. Cyclic GMP modulation of ion transport in rabbit ileum: studies with heat stable Escherichia coli enterotoxin. Am $\mathcal{f}$ Physiol 1982;253:G775-80.

2 Field M, Graf LH, Laird WJ, et al. Heat-stable enterotoxin of Escherichia coli: in vitro effects on guanylate cyclase, cyclic GMP concentration and ion transport in the small intestine. Proc Natl Acad Sci USA 1978;75:2800-4.

3 Eklund S, Jodal M, Lundgren O. The enteric nervous system participates in the secretory response to the heat stable enterotoxins of Escherichia coli in rats and cats. Neuroscience 1985;14:673-81.

4 Rolfe VE, Levin RJ. Enterotoxin Escherichia coli STa activates a nitric oxide-dependent myenteric plexus secreactivates a nitric oxide-dependent myenteric plexus secre
tory reflex in the rat ileum. $\mathcal{F}$ Physiol $1994 ; 475: 531-7$.

5 Nzegwu HC, Levin RJ. Tachykinin NK-2 receptor antagonist MN 10,627 selectively inhibits fluid secretion induced by luminal enterotoxin E. coli STa in the rat intestine in vivo. F Physiol 1997;499:100P.

6 Szurszweski JH, Miller SM. Physiology of prevertebral ganglia. In: Johnson LR (ed.), Physiology of the gastrointestinal tract. Vol 1. 3rd edn. New York: Raven Press, 1995:95-887.

7 Martin K, Kong TH, Renehan W, et al. Identification and function of brain stem neurones regulating rat ileal water
absorption. Am $\mathcal{F}$ Physiol 1989;257:G266-73.

8 Rolfe VE, Levin RJ. Ileal E coli STa activates jejunal but not colonic fluid secretion by a vagal reflex in the rat in vivo. $\mathcal{F}$
Physiol $1995 ; 487 \mathrm{P}: 36 \mathrm{P}$.

9 Rolfe VE, Brand MP, Heales SJR, et al. Tetrahydrobiopterin regulates cyclic GMP-dependent electrogenic $\mathrm{Cl}^{-}$secretion regulates cyclic GMP-dependent electrogenic $\mathrm{Cl}^{-}$sec
in mouse ileum in vitro. $\mathcal{F}$ Physiol $1997 ; 503: 347-52$.

10 Gaginella TS, Mascolo N, Izzo AA, et al. Nitric oxide as mediator of bisacodyl and phenopthalein laxative action: 
induction of nitric oxide synthase. 7 Pharmacol Exp Ther 1994;270:1239-45.

11 Izzo AA, Sautebin L, Rombola L, et al. The role of constitutive and inducible nitric oxide synthase in senna- and cascara-induced diarrhoea in the rat. Eur $\mathcal{f}$ Pharmacol 1997;323:93-7.

12 Schirgi-Degen A, Beubler E. Significance of nitric oxide in the stimulation of intestinal fluid absorption in the rat jejunum in vivo. Br $\mathcal{F}$ Pharmacol 1995;114:13-18.

13 Qui B, Pothoulakis C, Castagliuolo I, et al. Nitric oxide inhibits rat intestinal secretion by Clostridium difficile toxin A but not Vibrio cholerae enterotoxin. Gastroenterology 1996;111:409-18.

14 Nzegwu HC, Levin RJ. Duration of the hypersecretion induced by E. coli STa is reduced by L-NAME in intact but vitro. F Physiol 1994;475P:92P

15 Nzegwu HC, Levin RJ. Luminal capsaicin inhibits fluid zecrion secretion mediated by enterotoxin E. coli STa but not by exp 996;81:313-15

16 Jodal M, Holmgren S, Lundgren O, et al. Involvement of the myenteric plexus in the cholera toxin-induced net fluid secretion in the rat small intestine. Gastroenterology $1993 ; 10$

17 Holzer P. Local effector functions of capsaicin-sensitive sensory nerve endings: involvement of tachykinins, calcitonin gene-related peptide and other neuropeptides. Neuroscience 1988;24:739-68.

18 Castagliuolo I, LaMont JT, Letrourneau R, et al. Neuronal involvement in the intestinal effects of Clostridium difficile toxin A and Vibrio cholerae enterotoxin in rat ileum. Gastroenterology 1994;107:657-65.

19 Nocerino A, Iafusco M, Guandalini S. Cholera toxininduced small intestinal secretion has a secretory effect on the colon in the rat. Gastroenterology 1995;108:34-9.

20 Song Z, Brookes SJH, Costa M. Projections of specific morphological types of neurons within the myenteric plexus of phological types of neurons within the myenteric plexus of 1996;285:149-56.
21 Hubel KA, Renquist KS, Varley G. Secretory reflexes in ileum and jejunum: absence of remote effects. $\mathcal{F}$ Autonom Nerv Sys 1991;35:56-62.

22 Jodal $M$. Neuronal influences on intestinal transport. $f$ Intern Med 1990;228(suppl 1):125-32.

23 Jodal M, Lundgren O. Do intestinal villi secrete? Acta Physiol Scand 1996;158:115-18.

24 Bornstein JC, Furness JB, Costa M. Sources of excitatory synaptic inputs to neurochemically identified submucous neurones of guinea pig small intestine. 7 Autonom Nerv Sys 1987;18:83-91.

25 Kirchgessner A, Gershon MD. Identification of vagal and submucosal inputs to the myenteric plexus by retrograde and anterograde transport. In: Singer MV, Goebell $\mathrm{H}$ (eds), Nerves and the gastrointestinal tract. Lancaster: MTM Press Ltd, 1989:69-78.

26 Currie MG, Fok KF, Kato J, et al. Guanylin: an endogenous activator of intestinal guanylate cyclase. Proc Natl Acad Sci USA 1992;75:2800-4.

27 De Sauvage FJ, Keshav S, Kuang W-J, et al. Precursor structure, expression, and tissue distribution of human guanylin. Proc Natl Acad Sci USA 1992;89:9089-93.

28 Cohen MB, Witte DP, Hawkins JA, et al. Immunohistochemical localization of guanylin in the rat small intestine and in a human (Caco-2) intestinal cell line [abstract]. and in a human (Caco-2) intestin

$29 \mathrm{Li} \mathrm{Z}$, Taylor-Blake B, Light AR, et al. Immunocytological localization of guanylin, an endogenous ligand for C-type guanylate cyclase [abstract]. Gastroenterology 1995;108: A986.

30 Perkins A, Goy MF, Li Z. Uroguanylin is expressed by enterochromaffin cells in the rat gastrointestinal tract. Gastroenterology 1997;113:1007-14

31 Forssman W-G, Cetin Y, Hill O, et al. Review: guanylin is a new gastrointestinal hormone regulating water-electrolyte transport in the gut. In: Singer MV, Ziegler R, Rohr G (eds). Gastrointestinal tract and endocrine system (Falk Symposium 77). Lancaster: Kluwer Academic Publishers, posium 77). 